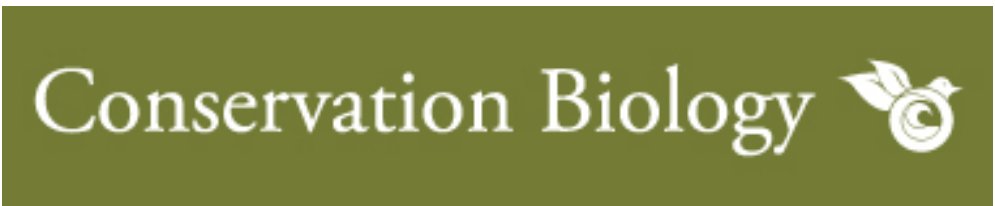

\title{
Mammalian megafauna in an uncertain world: ex situ management as insurance against extinction
}

\begin{tabular}{|c|c|}
\hline Journal: & Conservation Biology \\
\hline Manuscript ID & 19-658.R1 \\
\hline Wiley - Manuscript type: & Contributed Paper \\
\hline Keywords: & $\begin{array}{l}\text { Conservation planning, Mammals < Animals, Asia, Captive breeding, } \\
\text { Reintroduction }\end{array}$ \\
\hline Abstract: & $\begin{array}{l}\text { Many large-bodied mammalian species are experiencing collapses in } \\
\text { range or numbers due to escalating threats, mainly triggered by } \\
\text { humans. The persistence of species with populations reduced to } \\
\text { precarious levels may be heavily dependent on the fate of a very small } \\
\text { number of individual animals. Although in situ conservation aimed at } \\
\text { mitigating current threats is important, it may sometimes be insufficient } \\
\text { on its own. In these instances, the International Union for Conservation } \\
\text { of Nature provides guidelines for ex situ management and the } \\
\text { Convention on Biological Diversity (Article } 9 \text { ) indicates how it can support } \\
\text { the convention's objectives as an 'insurance' policy for conserving } \\
\text { species. The circumstances that justify its use are uncertain. We } \\
\text { evaluated current in situ extinction risk and ex situ management of } 43 \\
\text { species of Critically Endangered mammalian megafauna, and the } \\
\text { geopolitical variables related to governance, economics, and national } \\
\text { policy within their extant ranges. We showed that almost one third of the } \\
\text { world's terrestrial mammalian megafauna are not the subject of any ex } \\
\text { situ management. Most of these taxa occur in Africa and the Middle East, } \\
\text { especially in areas characterized by political uncertainty, such as border } \\
\text { zones or areas affected by armed conflicts. A further } 23 \% \text { of these taxa } \\
\text { in ex situ programs do not meet sustainability criteria. Strategic } \\
\text { conservation planning, such as the One Plan approach, is recommended } \\
\text { for improving ex situ management for these taxa. Given the escalating } \\
\text { trend in threats afflicting megafauna, ex situ management should be } \\
\text { considered more rigorously in conservation decision-making, particularly } \\
\text { for those in politically unstable regions to achieve Target } 12 \text { of the } \\
\text { Convention on Biological Diversity on preventing the extinction of } \\
\text { threatened species. }\end{array}$ \\
\hline
\end{tabular}

\section{SCHOLARONE" Manuscripts}


1 Mammalian megafauna in an uncertain world: ex situ management as insurance against

2 extinction

4 Abstract

5 Many large-bodied mammalian species are experiencing collapses in range or numbers due to

6 escalating threats, mainly triggered by humans. The persistence of species with populations

7 reduced to precarious levels may be heavily dependent on the fate of a very small number of

8 individual animals. Although in situ conservation aimed at mitigating current threats is

9 important, it may sometimes be insufficient on its own. In these instances, the International

10 Union for Conservation of Nature provides guidelines for ex situ management and the

11 Convention on Biological Diversity (Article 9) indicates how it can support the convention's

12 objectives as an 'insurance' policy for conserving species. The circumstances that justify its use

13 are uncertain. We evaluated current in situ extinction risk and ex situ management of 43 species

14 of Critically Endangered mammalian megafauna, and the geopolitical variables related to

15 governance, economics, and national policy within their extant ranges. We showed that almost

16 one third of the world's terrestrial mammalian megafauna are not the subject of any ex situ

17 management. Most of these taxa occur in Africa and the Middle East, especially in areas

18 characterized by political uncertainty, such as border zones or areas affected by armed conflicts.

19 A further $23 \%$ of these taxa in ex situ programs do not meet sustainability criteria. Strategic

20 conservation planning, such as the One Plan approach, is recommended for improving ex situ

21 management for these taxa. Given the escalating trend in threats afflicting megafauna, ex situ

22 management should be considered more rigorously in conservation decision-making, particularly 
23 for those in politically unstable regions to achieve Target 12 of the Convention on Biological

24 Diversity on preventing the extinction of threatened species.

25

26

27

28

29

30

31

32

33

34

35

36

\section{Introduction}

Although the maintenance of biodiversity in situ is the main objective for contemporary global conservation, this focus alone may not ensure the survival of species on the brink of extinction. Nonetheless, the utility of ex situ management for species conservation remains unclear and there are differing perspectives on its value as a meaningful approach (Balmford et al. 1996; Snyder et al. 1996; Conde et al. 2011; Pritchard et al. 2012; Fa et al. 2014; Brichieri-Colombi et al. 2019). The potential of ex situ management to support in situ conservation of species is, however, recognized in Article 9 of the Convention on Biological Diversity (CBD). The Convention text, drafted in 1992, states, crucially, that ex situ management should support in situ conservation measures (Convention on Biological Diversity 1992), indicating that there should be a relationship between what is happening in the wild and in captivity (Convention on Biological Diversity 1992).

\section{Ex situ is defined as conditions under which individuals are spatially restricted with} respect to their natural movement patterns or those of their progeny, are removed from many of their natural ecological processes, and individuals are managed on some level by humans (see also Williams \& Hoffman 2009; IUCN/SSC 2014; McGowan et al. 2017). Besides buying time, addressing the causes of primary threats and offsetting their effects, ex situ management can be used for population restoration or conservation introduction within or outside the species' indigenous range (IUCN/SSC 2013, 2014). The primary purpose of an ex situ program is most 
44 often claimed to be an "insurance policy", maintaining options for future conservation strategies 45 (Zimmermann 2010; McGowan et al. 2017).

There had been limited, if any, guidance proposed as to what such links between in situ

47 and ex situ managements might consist of, until IUCN's Species Survival Commission adopted

48 ex situ management guidelines in 2014 (IUCN/SSC 2014; see also McGowan et al. 2017). These

49 provided a decision-making process for determining whether ex situ management was

50 appropriate for a particular species, given its conservation needs, biological requirements and

51 available resources (McGowan et al. 2017).

In recent times, there has been a sharply increasing concern about species extinction risk

53 (e.g. Brondizio et al. 2019) and recognition of significant challenges in maintaining viable wild

54 populations of large-bodied mammals. For example, conservation efforts are struggling to arrest

55 the decline of various Critically Endangered taxa that have small and decreasing populations,

56 such as Sumatran rhino (Dicerorhinus sumatrensis) (Havmøller et al. 2016), Asiatic cheetah

57 (Aconinyx jubatus venaticus) (Farhadinia et al. 2017) and hirola (Beatragus hunteri) (Ali et al.

58 2018), suggesting that even intensive actions can be associated with ambiguous outcomes.

Here we explore whether there is a particular set of circumstances where ex situ management is likely to be of special value to an overall species recovery program for some of

61 the most conservation-dependent taxa, i.e. Critically Endangered terrestrial mammalian

62 megafauna. We excluded marine megafauna because they are difficult, if not impossible, to manage ex situ for conservation purposes (Klinowska 1991; Zimmermann 2010). Terrestrial

64 mammalian megafauna are particularly valuable in economic, ecological and societal terms, yet 65 are challenging and expensive to conserve (Ripple et al. 2014; Lindsey et al. 2017). We assumed 
66 that species insurance policy (ex situ management variables) should be formulated based on in

67 situ extinction risk (demographic variables) and its association with uncertainty in governance,

68 economics, and national policy (geopolitical variables) and so we explored this within the range

69 of 43 species of mammalian megafauna. We were particularly interested in understanding the

70 effect of political uncertainty, such as in border zones or other areas with armed conflicts, where

71 in situ conservation is likely to be compromised. Although these variables are informative as to

72 when an ex situ management population is potentially appropriate as a hedge against extinction,

73 other factors relating to feasibility and risk will also need to be considered in practice. Our

74 analyses may inform ex situ policies for Critically Endangered megafauna in such areas, and

75 demonstrate a strategic approach for identifying ex situ management as a potential priority for

76 highly threatened species.

\section{Methods}

\section{Species and geographic regions}

79 We defined as megafauna any mammalian species with adult body masses over $40 \mathrm{~kg}$ (for

80 ungulates and primates Stuart 1991) or $\geq 15 \mathrm{~kg}$ (for carnivores Ripple et al. 2014). The

81 megafauna in this paper represent four mammalian orders: Carnivora, Primates, Cetartiodactyla

82 and Perissodactyla. We included only Critically Endangered taxa (see IUCN 2017 for details on

83 criteria). The latest list of Critically Endangered mammals was obtained from the IUCN's Red

84 List of Threatened Species (with assessment date of 2015 to 2017 for different taxa). In total 43

85 taxa of Critically Endangered megafauna were identified, including 18 species, 23 subspecies 
87 Endangered at both species and subspecies levels; we therefore included all four gorilla subspecies with associated variables.

We defined five geographic regions: 1) African sub-Saharan, 2) Middle East/ SaharaSahel, 3) Asia (excluding the Middle East), 4) Europe and 5) North America. We assumed three a priori dimensions to fragility of situations in which ex situ management can be considered:

92 extinction risk (in situ demographic variables), insurance policy (ex situ management variables) and uncertainty in governance, economics, and national policy (geopolitical variables; Table 1).

In situ demographic and ex situ management variables

Demographic stochasticity, environmental stochasticity and random catastrophes can increase extinction risks in small populations (Lande et al. 2003). As a proxy for these extinction risks, we derived two in situ demographic variables from the IUCN Red List. They include the total population size of the taxa and its number of subpopulations. Accordingly, subpopulations are defined as geographically or otherwise distinct groups in the population between which there is little demographic or genetic exchange (www.redlist.org).

In addition, we collated four variables concerning ex situ management. An ex situ program was defined only by the presence of least two pairs of the species within the same facility, either inside (national ex situ program) or outside (international ex situ program) the range country. Although our evaluation is limited to the presence of ex situ founding populations, we acknowledge that case histories that involve too few individuals, or that lack effective management or infrastructure do not necessarily constitute a successful ex situ program. Accordingly, we queried the species' studbook managers, Association of Zoos and Aquariums (AZA; https://www.aza.org), the European Association of Zoos and Aquariums (EAZA; 
109

110

111

112

113

114

115

116

117

118

119

120

121

122

123

124

125

126

127

128

129

130

131

https://www.eaza.net) and Pan-African Association of Zoos and Aquaria (PAAZA;

http://www.zoosafrica.com). We also reviewed data on the presence of ex situ individuals within the species range countries, mainly using IUCN's Red List of Threatened Species. Data on ex situ numbers were obtained from Species360 Zoological Information Management Software (ZIMS; www.species360.org) as well as local accredited experts in range countries. We also asked the Southeast Asian Zoos and Aquariums Association (SEAZA) and the Pan-African Association of Zoos and Aquaria (PAAZA) for information concerning study taxa within their zoos, but none was forthcoming. Thus, we acknowledge that our paper could underestimate the prevalence of ex situ populations for some taxa, particularly in Asia. To evaluate the sustainability of ex situ populations, we used the inbreeding-avoidance criterion of $N_{e}>50$, known as the minimum viable effective population size, which prevent the dramatic short term consequences of inbreeding depression (Franklin et al. 2014). The last ex situ management variable was the endorsement of ex situ management as part of the conservation actions drafted for each taxon as part of its corresponding IUCN Red List assessment.

\section{Geopolitical variables}

Management practices do not occur in a vacuum; instead they are part of a wider context of international politics and multiscalar networks of social, cultural, political, economic and environmental factors (Hodgetts et al. 2019). Border zones and armed conflicts can compromise conservation resources, actions and outcomes (Hanson et al. 2009; Dallimer \& Strange 2015). Likewise, governance, economics and political support are associated with conservation performance of countries with regard to conserving their megafauna (Dickman et al. 2015; Lindsey et al. 2017). Accordingly, we included a geopolitical perspective to our analysis through four metrics as: 1) occurrence of the main population nucleus in a border zone (binary data); 2) 
132 political instability within the taxon's main extant range in terms of recent armed conflict (binary

133 data); 3) National Conservation Likelihood (NCL) (Dickman et al. 2015) and 4) Megafauna

134 Conservation Index (MCI) (Lindsey et al. 2017).

We defined a population as being a 'border' population if the species' main extant range

136 intersects with international borders and where the population nucleus persists in the country's

137 border zones, both assessed based on demographic and distributional data in the IUCN Red List.

138 To assess the spatial overlap between species ranges and armed conflicts, we compared the

139 geographic extant range of species within each country with the locations of armed conflicts

140 between 2008 and 2017. We adopted the Uppsala conflict database definition of armed conflict

141 as "a contested incompatibility that concerns government and/or territory where the use of armed

142 force between two parties, of which at least one is the government of a state, results in at least 25

143 battle-related deaths in one calendar year (Gleditsch et al. 2002)." We extended the above

144 definition to non-state based violence as well, e.g. between religious or ethnic groups. The geo-

145 referenced data on occurrence of armed conflict were obtained from Uppsala Conflict Data

146 Program (http://ucdp.uu.se).

Finally, we obtained an index of National Conservation Likelihood (NCL) from Dickman

148 et al. (2015) for each range country. The NCL was calculated based on 16 variables considered

149 as important indicators of likely conservation effectiveness in a country, based on governance,

150 economics and welfare, human population pressures, and conservation policy (see Table S2 for

151 more details). We also used the Megafauna Conservation Index (MCI) that assessed the spatial,

152 ecological and financial contributions of each country towards conservation of the world's

153 terrestrial megafauna (Lindsey et al. 2017). This is based on three metrics: 1) ecological 
154 contribution, defined as megafauna cumulative distribution based on the number of extant 155 megafauna within each country's borders, 2) protected area contribution measured by the 156 percentage of megafauna habitat that is strictly protected and 3) financial contribution 157 represented by the percentage of each country's national gross domestic product (GDP) allocated 158 to conservation (see Table S3 for countries’ MCI).

159

160 161

162 171 (Oksanen et al. 2013).

\section{Data analysis}

We used Non-metric Multidimensional Scaling (NMDS) to explore patterns of variation among the taxa in their demographic and geopolitical characteristics. As a method for exploring multivariate patterns, NMDS has several advantages compared to other options, including a reduced arch effect, gradient recovery enhancement, and the ability for the user to specify the number of dimensions in which to represent n-dimensional raw data (Podani 2005).

NMDS is an iterative procedure which seeks to represent the rank orders of dissimilarity between entities in the derived ordination space. Each ordination started with 20 random configurations, and proceeded through 400 iterations for each of four dimensions. We chose the Bray-Curtis dissimilarity index which has a good rank order relation to ordering species along different variables. The data were transformed to their square roots to reduce the influence of outlying values. The transformed values were then submitted to Wisconsin standardization

We used a Shepard plot where ordination distances are plotted against observed dissimilarities, and two statistics of goodness of fit, referred to as non-metric fit $R^{2}$ and linear fit $R^{2}$ (Figure $\mathrm{S} 1$ ) to assess the performance of the ordination. The stress value on species position was also optimized, representing the difference between the distances in the reduced dimension 
176 compared to the complete multidimensional space. Hence low values of stress indicate that the

177 species rank differences are faithfully reproduced by the ordination. As a rule of thumb, stress

$178<0.05$ and $<0.1$ give an 'excellent' and 'good' representation, respectively. Stress $<0.2$ can still

179 lead to a usable picture, although for values at the upper end of this range there is potential to

180 mislead (Clarke 1993). We also fitted a smooth surface using a generalized additive model

181 (GAM) to assess the contribution of each variable to the NMDS ordination with restricted

182 maximum likelihood (REML) estimation (Oksanen et al. 2013). For each variable, we calculated

183 adjusted $R^{2}$ and the approximate significance of smooth terms to check the linearity hypothesis

184 of relationship between the species composition.

Analysis of similarity (ANOSIM) using the Bray-Curtis distance index was used to test the statistical significance of differences in the ordination scores with respect to geographic

187 regions. This nonparametric permutation procedure is based only on the rank order of the 188 similarity matrix values underlying an ordination plot to calculate an $R$ test statistic. Both NMDS 189 and ANOSIM were run using the 'vegan' package (Oksanen et al. 2013). We conducted all 190 analyses in $R$ (R Development Core Team 2013).

\section{Results}

192 There are 43 Critically Endangered terrestrial mammalian megafauna (Table S1), spanning 57 193 countries across Asia ( $\mathrm{n}=10)$, Sahelo-Sahara/Middle East region $(\mathrm{n}=17)$, and sub-Sahara Africa 194 ( $\mathrm{n}=26)$. Outside Africa and Asia, the Balkan lynx (Lynx lynx balcanicus) persists across three 195 east European countries, while the red wolf (Canis rufus) is the only representative of Critically 196 Endangered megafauna in North America (Figure 1). 
Current in situ population sizes differ substantially among species, with $55.8 \%(n=24)$ of

198

199

200

201

202

203

204

205

206

207

208

209

210

211

212

populations estimated to comprise fewer than 250 individuals, whereas a few others $(n=8)$

comprise more than 1,000 individuals (Table S1). Except from six taxa, all other species (86.0\%)

are declining in numbers. In total, $44.2 \%(\mathrm{n}=19)$ of the evaluated taxa mainly occur along

international boundaries (Table S1). Armed conflicts have recently occurred within the range of $30.2 \%(n=13)$ of the Critically Endangered megafauna, predominantly in Sahelo-Sahara or subSaharan Africa.

We found that 14 taxa (32.6\%) lack any ex situ programs, either within or outside their ranges. Additionally, $23.3 \%$ of the ex situ populations $(n=10)$ do not meet the inbreedingavoidance criterion of $N_{e}>50$ as a proxy for population suitability. There are international ex situ programs for $44.2 \%(n=19)$ of the species while more species $(67.4 \%, n=29)$ are associated with a national ex situ program within at least one range country. Ex situ management was explicitly endorsed during the Red List assessment for only 15 taxa (34.9\%), almost exclusively belonging to herbivores $(\mathrm{n}=14)$. Those taxa without any ex situ endorsement tend to have ranges in Africa or the Middle East (Figure 2), whereas the rest of Asian species usually have ex situ support, either inside or outside the range countries.

Apart from rehabilitation efforts, eight species were associated with reinforcement or reintroduction programs, i.e. enhancing population viability or re-establishing a viable population within the species' indigenous range, respectively (IUCN/SSC 2013, 2014), such as red wolf Canis rufus, Addax Addax nasomaculatus, Sumatran orangutan Pongo abelii, Bornean orangutan Pongo pygmaeus, Dama gazelle Nanger dama, black rhinoceros Diceros bicornis, western lowland Gorillas Gorilla gorilla gorilla and western chimpanzee Pan troglodytes verus. 
There was no evidence that the taxa in different geographic regions differed with respect

220

221

222

223

224

225

226

227

to our demographic and geopolitical predictors (ANOSIM $R=-0.01546, P=0.54$ ). However,

when the two regions with the highest abundance of taxa were examined in isolation, the composition of demographic and geopolitical predictors were significantly different (ANOSIM $R$ $=0.2059, P=0.03)$. Four variables, NationalExsitu, InternationalExsitu, BorderZone and Instability, accounted for the highest proportion of explained deviance, varying between 66.2 and $88.9 \%$ (see Table 1 for variable description). In contrast, the population size of each taxon, either in the wild or captivity as well as NCL and MCI made only minor contributions to the ordination of the species with nonlinear fitted surface $(P>0.05$; Table 1$)$.

The two key variables describing geopolitical uncertainty, i.e. BorderZone and Instability were ordinated far from those variables in favor of the ex situ management, such as NationalExsitu, InternationalExsitu and ExSituEndorsed.

\section{Discussion}

Around one third of the world's Critically Endangered terrestrial mammalian megafauna are not supported by any ex situ management. These taxa without ex situ management mainly persist in uncertain situations such as border zones or regions experiencing armed conflicts, particularly in Africa and the Middle East (Figure 2). Importantly, another 23\% of taxa are not sustainably represented in ex situ programs. Considering the current trends of dynamic threats to these megafauna, ex situ management, endorsed in the Article 9 of the CBD, may merit more attention as an option in conservation decision-making, particularly in politically uncertain situations, acknowledging the extra challenges its implementation presents. 
Border zones and armed conflicts have compromising effects on conservation resources,

241

242

243

244

245

246

247

248

249

250

251

252

253

254

255

256

257

258

259

260

261

262 actions and outcomes (Hanson et al. 2009; Dallimer \& Strange 2015; Gaynor et al. 2016). They

can sometimes serve as refugia for rare species due to restrictions on human access (Lee et al.

2007; Melovski et al. 2019) or halt hunting or extractive industries (Lindsell et al. 2011).

However, more often socio-political boundaries impose substantial costs on biodiversity and ecosystem conservation by fragmenting ownership, governance, and management (Dallimer \& Strange 2015; Brito et al. 2018; O’Kelly et al. 2018). Likewise, armed conflicts often lead to withdrawal of conservation funding by international development programs (Hanson et al. 2009;

Gaynor et al. 2016). Yet sustained conservation efforts in conflict zones, incorporating conservation issues into military, relief, and reconstruction planning and rapid interventions following ceasefires, may help to save many at-risk populations (Hanson et al. 2009; Hanson 2011; Daskin \& Pringle 2018). However, the effective population size may drop so severely during the political instability that reversal is unlikely without ex situ management.

Although the attention of CBD contracting Parties is drawn, in Article 9 of the convention text, to adopting ex situ measures, as far as possible and as appropriate, and predominantly for the purpose of complementing in situ actions (Convention on Biological Diversity 1992), conservationists generally do not consider ex situ interventions until in situ approaches are thought to have low prospects of success (Zimmermann 2010; Pritchard et al. 2012). For example, action plans generally have not considered ex situ management as part of the conservation solutions, even for Critically Endangered megafauna with decreasing population trends existing in geopolitically fragile regions (Hillman-Smith et al. 1986; Emslie \& Brooks 1999; IUCN/SSC 2012; Antelope Specialist Group 2017). Ex situ management cannot reverse the effect of failed in situ conservation if implemented too late (Martin et al. 2012). We 
263 therefore propose that, as far as possible, ex situ management should be incorporated within 264 conservation action plans of the Critically Endangered megafauna in politically uncertain 265 situations. We note, however, that this requires a careful approach so that investments in ex situ 266 management do not detract from investments in in situ strategies.

Where the ex situ approach is deemed advisable, there will be some important issues to consider, including where the program should be sited. This will require balancing the security of the animals, which will comprise a significant proportion of the remaining extant population, and 270 staff who may be at risk in conflict zones. When political instability occurs within the range of 271 species but the central states cannot be described as 'failed', as is the case of the majority of taxa 272 evaluated here, investment and capacity building within range countries is a more promising 273 approach, and likely to attract more widespread support, rather than moving individuals outside 274 the range states which could be perceived as having elements of neocolonial conservation, and 275 therefore not attract the support of public and scholars (Hayward et al. 2018). Likewise, some 276 species perhaps do not need ex situ management. A clear example of this is the African wild 277 donkey Equus africanus. There are large populations of this species outside their native range 278 that are argued to contribute to biodiversity conservation (Lundgren et al. 2018; Schlaepfer 279 2018). Other conservationists believe that the origin of the animals matters (Pauchard et al. 280 2018).

To take into account constraints and uncertainties about when and how to implement ex 282 situ management, the IUCN SSC has proposed a five-step process: 1) status review; 2) potential 283 roles of ex situ management; 3) how the ex situ population can meet identified roles; 4) appraisal 284 of the feasibility and risks and 5) decision-making in the interests of transparency about the 
285 cultural, values and knowledge frameworks that are used (IUCN/SSC 2014; McGowan et al.

286 2017). Therefore, if a Critically Endangered taxon does not pass this five-step decision-making

287 process, it suggests that the constraints and uncertainties of implementing an ex situ management

288 may be non-beneficial to the overall recovery. For example, endorsed ex situ plans during the

289 Red List assessment almost exclusively belong to herbivores. In contrast, ex situ management is

290 a resource intensive endeavor and reinforcement/reintroduction programs can experience high

291 chance of failure in large carnivores (Snyder et al. 1996; Jule et al. 2008; Hayward \& Somers

292 2009; Zimmermann 2010). Therefore, further research is desirable to enhance the success rate of

293 reinforcement, reintroduction and translocation attempts for carnivorous megafauna, which is

294 increasingly encouraged by governments (Breitenmoser et al. 2014; Qin et al. 2015; Chestin et

295 al. 2017; Farhadinia et al. 2017; Gray et al. 2017).

The management of at-risk species, particularly in less-stable parts of the world, requires

297 a spectrum of interventions that can range from habitat protection to the ex situ programs with

298 the eventual aim of reinforcement/reintroduction into the wild (Conde et al. 2013; Canessa et al.

299 2016). Consequently, some have argued that the boundary between ex situ and in situ

300 management is becoming blurred (Pritchard et al. 2012; Redford et al. 2012). To bridge between

301 conservation interventions holistically, the IUCN SSC Conservation Planning Specialist Group

302 advocates the One Plan approach (Byers et al. 2013; Conde et al. 2013). This is the development

303 of unified management strategies and conservation actions by all responsible parties for all

304 populations of a species, whether inside or outside their natural range (Byers et al. 2013).

In an ideal world, we might wish that in situ strategies would be sufficient to guarantee

306 that no megafauna species goes extinct. However, there are cases where this is doubtful and 
307 properly implemented ex situ programs have arguably contributed to the recovery of several 308 megafauna (Hedrick \& Fredrickson 2010; Stanley-Price 2016). Ex situ measures could 309 complement in situ protection if it is well targeted and resources used effectively and efficiently.

310 Given the reported poor progress towards achieving Aichi Target 12 of the CBD to reversing the 311 declines of the most threatened species (Tittensor et al. 2014), it is clearly vital that all potential

312 responses are considered and that they are deployed strategically where they will have the 313 biggest positive impact. As human armed conflicts are predicted to increase in association with 314 the effects of global climate change (Burke et al. 2009), mammalian megafauna, particularly 315 those with small populations inhabiting politically non-stable regions, can benefit from such 316 strategic and holistic support.

317 Data availability The data that support the findings of this study are provided in the manuscript.

\section{$318 \quad$ References}

319 Ali AH, Kauffman MJ, Amin R, Kibara A, King J, Mallon D, Musyoki C, Goheen JR. 2018. 320 Demographic drivers of a refugee species: large-scale experiments guide strategies for 321 reintroductions of hirola. Ecological Applications 28:275-283.

322 Antelope Specialist Group. 2017. Alcelaphus buselaphus ssp. tora. Available from http://dx.doi.org/10.2305/IUCN.UK.2017-2.RLTS.T810A50180985.en (accessed June 5, 2018).

325 Balmford A, Mace GM, Leader-Williams N. 1996. Designing the ark: setting priorities for 326 captive breeding. Conservation biology 10:719-727. Wiley Online Library.

327 Breitenmoser U, Pittet M, Avgan B, Askerov, E. Breitenmoser-Würsten C, Ransom C. 2014. 

Recovery of the Leopard in Azerbaijan. Zoological Society of London, United Kingdom.

Brichieri-Colombi TA, Lloyd NA, McPherson JM, Moehrenschlager A. 2019. Limited contributions of released animals from zoos to North American conservation translocations. Conservation Biology 33:33-39.

Brito JC, Durant SM, Pettorelli N, Newby J, Canney S, Algadafi W, Rabeil T, Crochet P, Pleguezuelos JM, Wacher T. 2018. Armed conflicts and wildlife decline: Challenges and recommendations for effective conservation policy in the Sahara-Sahel. Conservation Letters 11:e12446.

Brondizio E, Settele J, Diaz S, Ngo T. 2019. Global assessment report on biodiversity and ecosystem services of the Intergovernmental Science-Policy Platform on Biodiversity and Ecosystem Services. IPBES Secretariat, Bonn.

Burke MB, Miguel E, Satyanath S, Dykema JA, Lobell DB. 2009. Warming increases the risk of civil war in Africa. Proceedings of the national Academy of sciences 106:20670-20674.

Byers O, Lees C, Wilcken J, Schwitzer C. 2013. The One Plan Approach: The philosophy and implementation of CBSG's approach to integrated species conservation planning. WAZA Magazine 14:2-5.

Canessa S, Converse SJ, West M, Clemann N, Gillespie G, McFadden M, Silla AJ, Parris KM, McCarthy MA. 2016. Planning for ex situ conservation in the face of uncertainty. Conservation Biology 30:599-609.

Chestin IE, Paltsyn MY, Pereladova OB, Iegorova L V, Gibbs JP. 2017. Tiger re-establishment potential to former Caspian tiger (Panthera tigris virgata) range in Central Asia. Biological 
conservation 205:42-51.

350 Clarke KR. 1993. Non-parametric multivariate analyses of changes in community structure. Austral ecology 18:117-143.

352 Conde DA, Colchero F, Gusset M, Pearce-Kelly P, Byers O, Flesness N, Browne RK, Jones OR. 2013. Zoos through the lens of the IUCN Red List: a global metapopulation approach to support conservation breeding programs. PLOS ONE 8:e80311.

355 Conde DA, Flesness N, Colchero F, Jones OR, Scheuerlein A. 2011. An Emerging Role of Zoos 356 to Conserve Biodiversity. Science 331:1390-1391.

Convention on Biological Diversity. 1992. Convention on Biological Diversity.

Dallimer M, Strange N. 2015. Why socio-political borders and boundaries matter in conservation. Trends in Ecology \& Evolution 30:132-139.

360

361

362

Daskin JH, Pringle RM. 2018. Warfare and wildlife declines in Africa's protected areas. Nature 553:328.

Dickman AJ, Hinks AE, Macdonald EA, Burnham D, Macdonald DW. 2015. Priorities for global felid conservation. Conservation Biology 29:854-864.

Emslie R, Brooks M. 1999. African rhino: status survey and conservation action plan. IUCN.

Fa JE, Gusset M, Flesness N, Conde DA. 2014. Zoos have yet to unveil their full conservation potential. Animal Conservation 17:97-100. Wiley Online Library.

Farhadinia MS, Hunter LTB, Jourabchian AR, Hosseini-Zavarei F, Akbari H, Ziaie H, Schaller GB, Jowkar H. 2017. The critically endangered Asiatic cheetah Acinonyx jubatus venaticus 
in Iran: a review of recent distribution, and conservation status. Biodiversity and Conservation:1-20.

Franklin IR, Allendorf FW, Jamieson IG. 2014. The 50/500 rule is still valid—reply to Frankham et al. Biolocical Conservation 176:284-285.

Gaynor KM, Fiorella KJ, Gregory GH, Kurz DJ, Seto KL, Withey LS, Brashares JS. 2016. War and wildlife: linking armed conflict to conservation. Frontiers in Ecology and the Environment 14:533-542.

Gleditsch NP, Wallensteen P, Eriksson M, Sollenberg M, Strand H. 2002. Armed conflict 19462001: A new dataset. Journal of peace research 39:615-637.

Gray TNE et al. 2017. A framework for assessing readiness for tiger Panthera tigris reintroduction: a case study from eastern Cambodia. Biodiversity and Conservation 26:2383-2399.

Hanson T. 2011. War and biodiversity conservation: the role of warfare ecology. Pages 125-132 Warfare Ecology. Springer.

Hanson T, Brooks TM, Da Fonseca GAB, Hoffmann M, Lamoreux JF, Machlis G, Mittermeier CG, Mittermeier RA, Pilgrim JD. 2009. Warfare in biodiversity hotspots. Conservation Biology 23:578-587.

Havmøller RG, Payne J, Ramono W, Ellis S, Yoganand K, Long B, Dinerstein E, Williams AC, Putra RH, Gawi J. 2016. Will current conservation responses save the critically endangered Sumatran rhinoceros Dicerorhinus sumatrensis? Oryx 50:355-359. Cambridge University Press. 
Hayward MW, Ripple WJ, Kerley GIH, Landman M, Plotz RD, Garnett ST. 2018. Neocolonial conservation: is moving rhinos to Australia conservation or intellectual property loss. Conservation Letters 11:e12354. Wiley Online Library.

Hayward MW, Somers M. 2009. Reintroduction of top-order predators. John Wiley \& Sons.

Hedrick PW, Fredrickson R. 2010. Genetic rescue guidelines with examples from Mexican wolves and Florida panthers. Conservation Genetics 11:615-626.

Hillman-Smith K, ma Oyisenzoo M, Smith F. 1986. A last chance to save the northern white rhino? Oryx 20:20-26.

Hodgetts T, Burnham D, Dickman A, Macdonald EA, Macdonald DW. 2019. Conservation geopolitics. Conservation Biology 33:250-259.

IUCN/SSC. 2012. Regional conservation strategy for the cheetah and African wild dog in west, north and central Africa. Gland, Switzerland.

IUCN/SSC. 2013. Guidelines for reintroductions and other conservation translocations. Version 1.0. IUCN Species Survival Commission Gland, Switzerland.

IUCN/SSC. 2014. Guidelines on the Use of Ex Situ Management for Species Conservation. Version 2.0. Gland, Switzerland.

IUCN. 2017. The IUCN Red List of Threatened Species. Version 2017-3. Available from http://www.iucnredlist.org (accessed April 5, 2018).

Jule KR, Leaver LA, Lea SEG. 2008. The effects of captive experience in reintroduction survival in carnivores: a review and analysis. Biological Conservation 141:355-363. 
410 Klinowska M. 1991. Dolphins, porpoises and whales of the world: the IUCN Red Data Book. IUCN, Gland, Switzerland.

412

413

414

415

416

417

Lande R, Engen S, Saether B-E. 2003. Stochastic population dynamics in ecology and conservation. Oxford University Press.

Lee SD, Jabłoński PG, Higuchi H. 2007. Winter foraging of threatened cranes in the Demilitarized Zone of Korea: behavioral evidence for the conservation importance of unplowed rice fields. Biological Conservation 138:286-289.

Lindsell JA, Klop E, Siaka AM. 2011. The impact of civil war on forest wildlife in West Africa: mammals in Gola Forest, Sierra Leone. Oryx 45:69-77.

Lindsey PA, Chapron G, Petracca LS, Burnham D, Hayward MW, Henschel P, Hinks AE, Garnett ST, Macdonald DW, Macdonald EA. 2017. Relative efforts of countries to conserve world's megafauna. Global Ecology and Conservation 10:243-252.

Lundgren EJ, Ramp D, Ripple WJ, Wallach AD. 2018. Introduced megafauna are rewilding the Anthropocene. Ecography 41:857-866. Wiley Online Library.

Martin TG, Nally S, Burbidge AA, Arnall S, Garnett ST, Hayward MW, Lumsden LF, Menkhorst P, McDonald-Madden E, Possingham HP. 2012. Acting fast helps avoid extinction. Conservation Letters 5:274-280.

McGowan PJK, Traylor-Holzer K, Leus K. 2017. IUCN Guidelines for determining when and how ex situ management should be used in species Conservation. Conservation Letters 10:361-366.

Melovski D, von Arx M, Avukatov V, Breitenmoser-Würsten C, Đurović M, Elezi R, Gimenez 
431

432

433

434

435

436

437

438

439

440

441

442

443

444

445

446

447

448

449

450

451

O, Hoxha B, Hristovski S, Ivanov G. 2019. Using questionnaire surveys and occupancy modelling to identify conservation priorities for the Critically Endangered Balkan lynx Lynx lynx balcanicus. Oryx:1-9.

O’Kelly HJ, Rowcliffe JM, Durant SM, Milner-Gulland EJ. 2018. Robust estimation of snare prevalence within a tropical forest context using N-mixture models. Biological Conservation 217:75-82.

Oksanen J, Blanchet FG, Kindt R, Legendre P, Minchin PR, O'hara RB, Simpson GL, Solymos P, Stevens MHH, Wagner H. 2013. Package 'vegan.' Community ecology package, version 2.

Pauchard A, Meyerson LA, Bacher S, Blackburn TM, Brundu G, Cadotte MW, Courchamp F, Essl F, Genovesi P, Haider S. 2018. Biodiversity assessments: Origin matters. PLoS biology 16:e2006686. Public Library of Science.

Podani J. 2005. Multivariate exploratory analysis of ordinal data in ecology: pitfalls, problems and solutions. Journal of Vegetation Science 16:497-510.

Pritchard DJ, Fa JE, Oldfield S, Harrop SR. 2012. Bring the captive closer to the wild: redefining the role of ex situ conservation. Oryx 46:18-23.

Qin Y, Nyhus PJ, Larson CL, Carroll CJW, Muntifering J, Dahmer TD, Jun L, Tilson RL. 2015. An assessment of South China tiger reintroduction potential in Hupingshan and Houhe National Nature Reserves, China. Biological Conservation 182:72-86.

R Development Core Team. 2013. R: A language and environment for statistical computing.

Redford KH, Jensen DB, Breheny JJ. 2012. Integrating the captive and the wild. Science 
338:1157-1158.

453

454

455

456

457

458

459

460

461

462

463

464

465

466

467

468

469

470

471

Ripple WJ et al. 2014. Status and ecological effects of the World's largest carnivores. Science 343:1241484.

Schlaepfer MA. 2018. Do non-native species contribute to biodiversity? PLoS biology 16:e2005568. Public Library of Science.

Snyder NFR, Derrickson SR, Beissinger SR, Wiley JW, Smith TB, Toone WD, Miller B. 1996. Limitations of Captive Breeding in Endangered Species Recovery. Conservation Biology 10:338-348.

Stanley-Price MR. 2016. Reintroduction as an antelope conservation solution. Antelope Conservation: From Diagnosis to Action:217. John Wiley \& Sons.

Stuart AJ. 1991. Mammalian extinctions in the Late Pleistocene of northern Eurasia and North America. Biological Reviews 66:453-562.

Tittensor DP, Walpole M, Hill SLL, Boyce DG, Britten GL, Burgess ND, Butchart SHM, Leadley PW, Regan EC, Alkemade R. 2014. A mid-term analysis of progress toward international biodiversity targets. Science 346:241-244.

Williams SE, Hoffman EA. 2009. Minimizing genetic adaptation in captive breeding programs: A review. Biological Conservation 142:2388-2400.

Zimmermann A. 2010. The role of zoos in contributing to in situ conservation. Wild mammals in captivity: Principles and techniques for zoo management:281-287. University of Chicago Press. 


\section{$474 \quad$ Figure legends}

475

476 Figure 1 Global distribution of critically endangered megafauna. (A) Asia, (B) southeast Asia, 477 (C) Sahelo-Sahara/Middle East, and (D) Sub-Saharan Africa. Only the red wolf living in the US 478 is not shown. The Balkan lynx is shown with other species on the Sahelo-Sahara/Middle East 479 map. See Table S4 for the courtesy of species silhouette.

480

481

482

483

Figure 2 Non-metric multi-dimensional scaling (NMDS) ordination of the demographic and

484 geopolitical variables for critically endangered megafauna. Color points represent taxa connected 485 to the geographic group centroid; those that are more similar to one another are ordinated closer 486 together. See Table 1 for the full species names.

487

488

489

490

491

492

493

494

495

496 
497 Table 1 Description of demographic, ex situ management and geopolitical variables evaluated for

49843 critically endangered mammalian megafauna. The contribution of each variable to the NMDS

499 ordination (adjusted $R^{2}$, the approximate significance of smooth terms and the percentage of

500 deviance described by each variable) was estimated after fitting a smooth surface using a

501 generalized additive model (GAM).

\begin{tabular}{|c|c|c|c|c|c|c|}
\hline $\begin{array}{c}\text { Variable } \\
\text { type }\end{array}$ & Variable name & Description & Reference & $R^{2}$ & $\boldsymbol{P}$ & $\begin{array}{l}\text { Deviance } \\
\text { explained }\end{array}$ \\
\hline \multirow[t]{2}{*}{ Demographic } & InsituPopulation & The in situ population size & IUCN Red List & 0.012 & 0.32 & $2.2 \%$ \\
\hline & SubpopulationNumber & $\begin{array}{l}\text { The number of in situ } \\
\text { subpopulation(s) }\end{array}$ & IUCN Red List & 0.099 & $<0.01$ & $16.5 \%$ \\
\hline \multirow{5}{*}{$\begin{array}{l}\text { Ex situ } \\
\text { management }\end{array}$} & & & IUCN Red & & & \\
\hline & ExsituPopulation & The ex situ population size & $\begin{array}{l}\text { List/AZA/EAZA/ } \\
\text { ZAA/ZIMS }\end{array}$ & 0.208 & 0.04 & $28.8 \%$ \\
\hline & ExSituEndorsed & $\begin{array}{l}\text { Is ex situ management } \\
\text { endorsed in the corresponding } \\
\text { IUCN Red List assessment? }\end{array}$ & IUCN Red List & 0.330 & $<0.01$ & $36.9 \%$ \\
\hline & NationalExsitu & $\begin{array}{l}\text { Is there any ex situ population } \\
\text { within range countries? }\end{array}$ & $\begin{array}{l}\text { IUCN Red } \\
\text { List/AZA/EAZA/ZIMS }\end{array}$ & 0.858 & $<0.01$ & $88.9 \%$ \\
\hline & InternationalExsitu & $\begin{array}{l}\text { Is there any ex situ population } \\
\text { outside range countries? }\end{array}$ & $\begin{array}{l}\text { IUCN Red } \\
\text { List/AZA/EAZA/ZIMS }\end{array}$ & 0.652 & $<0.01$ & $70.9 \%$ \\
\hline \multirow[t]{4}{*}{ Geopolitical } & BorderZone & $\begin{array}{l}\text { Is the main population nucleus } \\
\text { occurs along border zone? }\end{array}$ & IUCN Red List & 0.595 & $<0.01$ & $66.2 \%$ \\
\hline & Instability & $\begin{array}{l}\text { Is there recent armed conflict } \\
\text { within the taxa's main range? }\end{array}$ & $\begin{array}{l}\text { Uppsala Conflict Data } \\
\text { Program }\end{array}$ & 0.811 & $<0.01$ & $85.5 \%$ \\
\hline & MCI & $\begin{array}{l}\text { Megafauna Conservation } \\
\text { Index }\end{array}$ & (Lindsey et al. 2017) & 0.044 & 0.19 & $6.9 \%$ \\
\hline & NCL & National Conservation & (Dickman et al. 2015) & 0.081 & 0.11 & $11.5 \%$ \\
\hline
\end{tabular}


Figure 1A

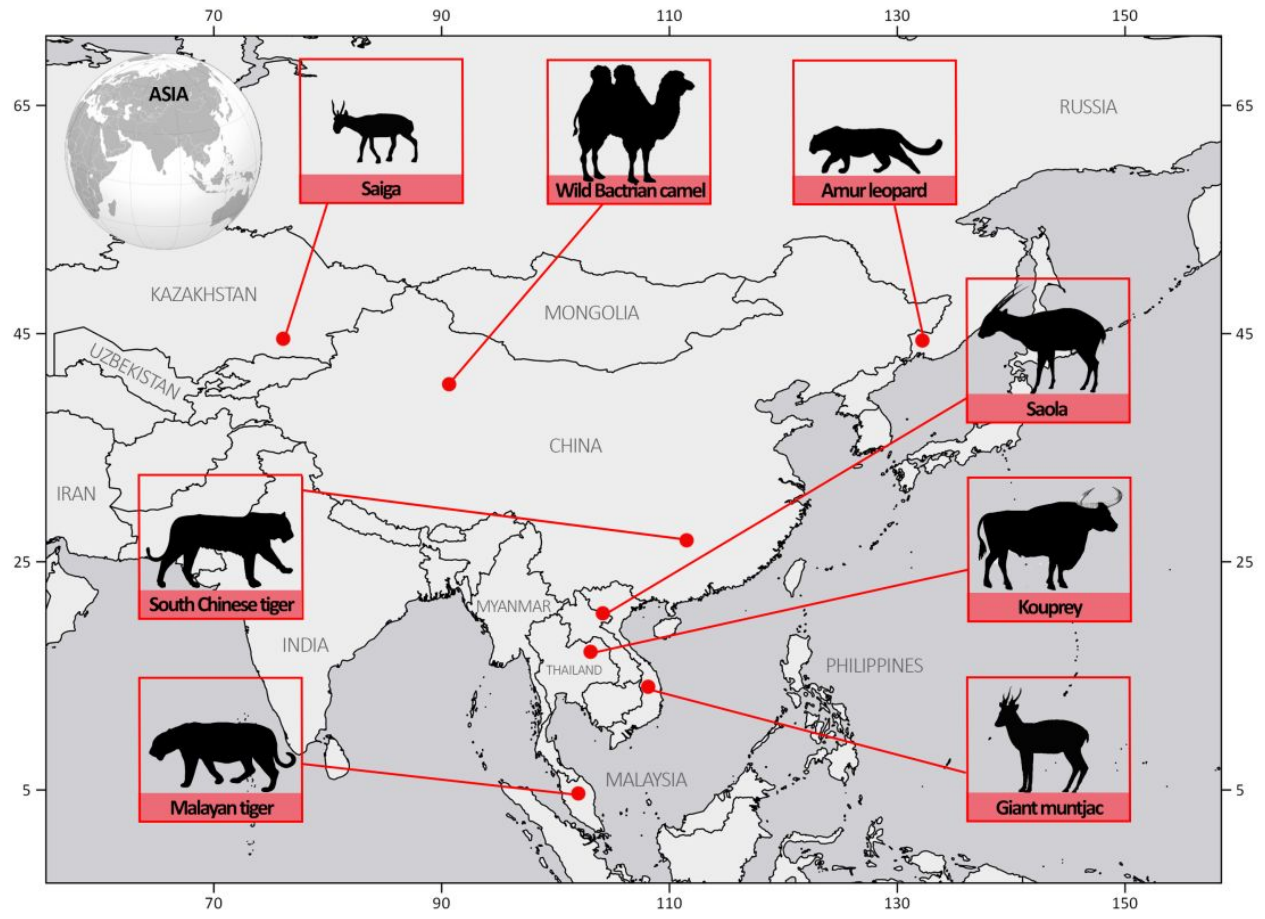

Figure 1B

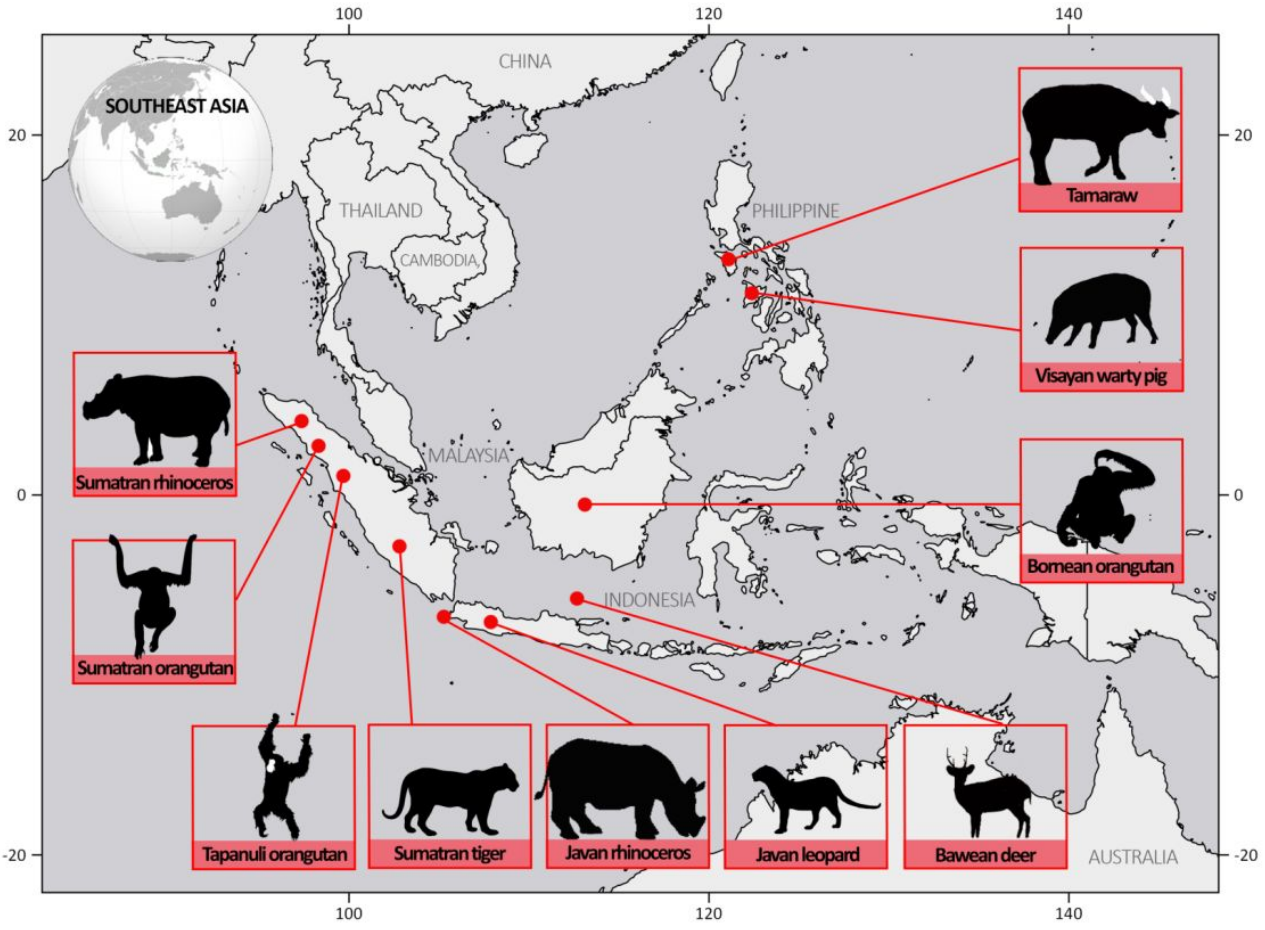




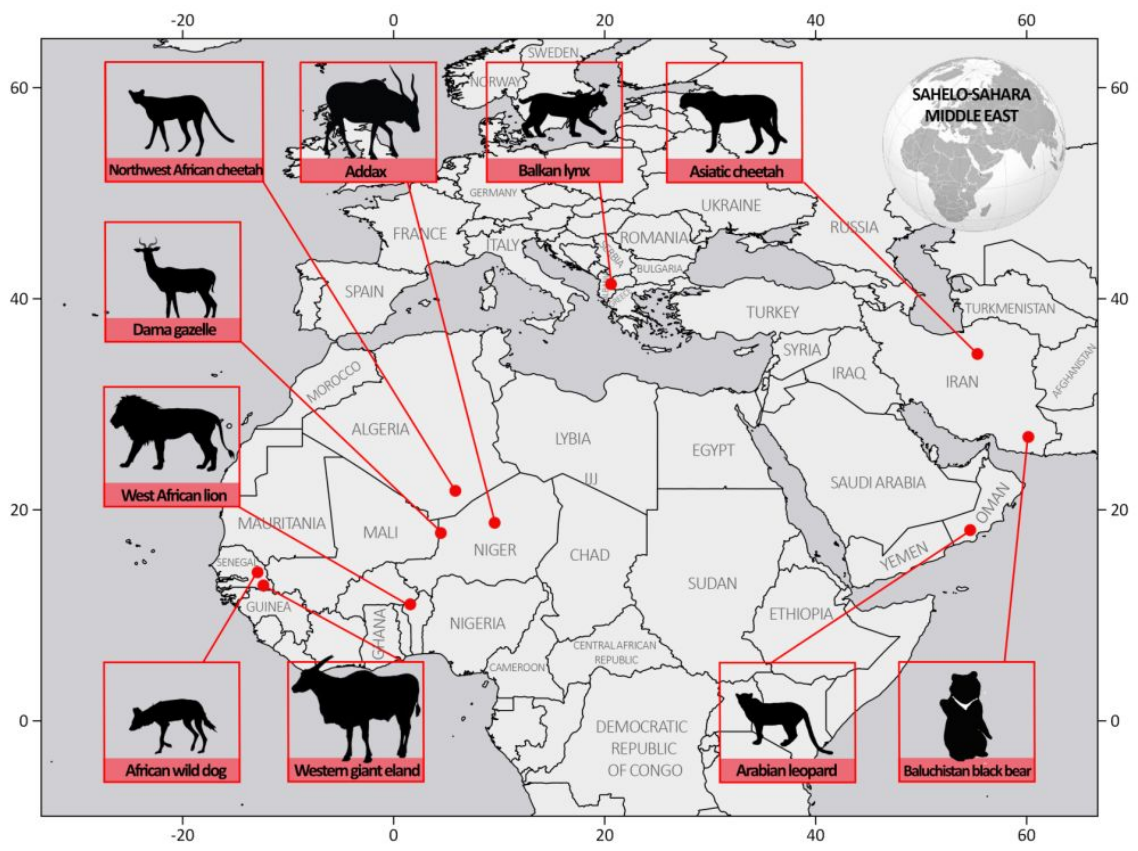

509 Figure 1D

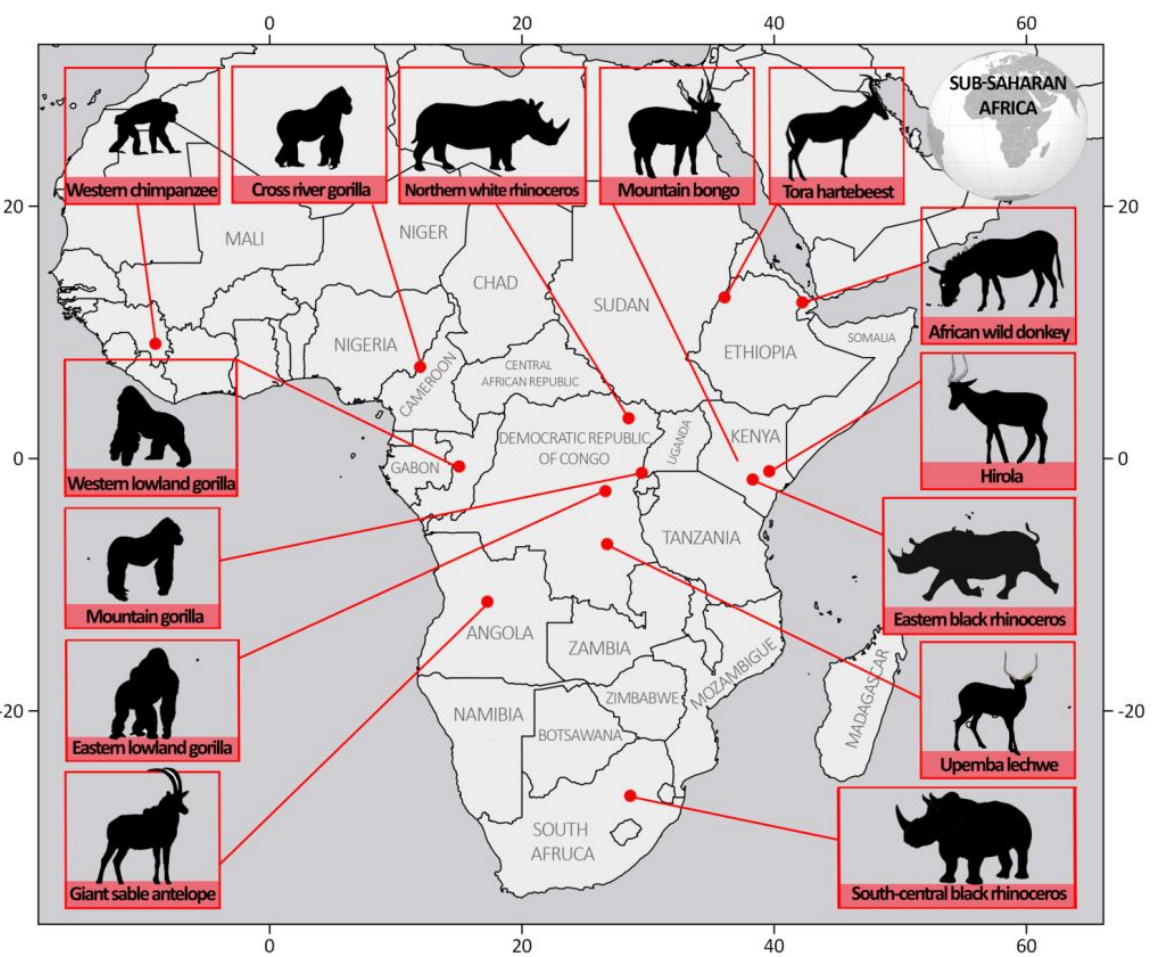


511 Figure 2

512

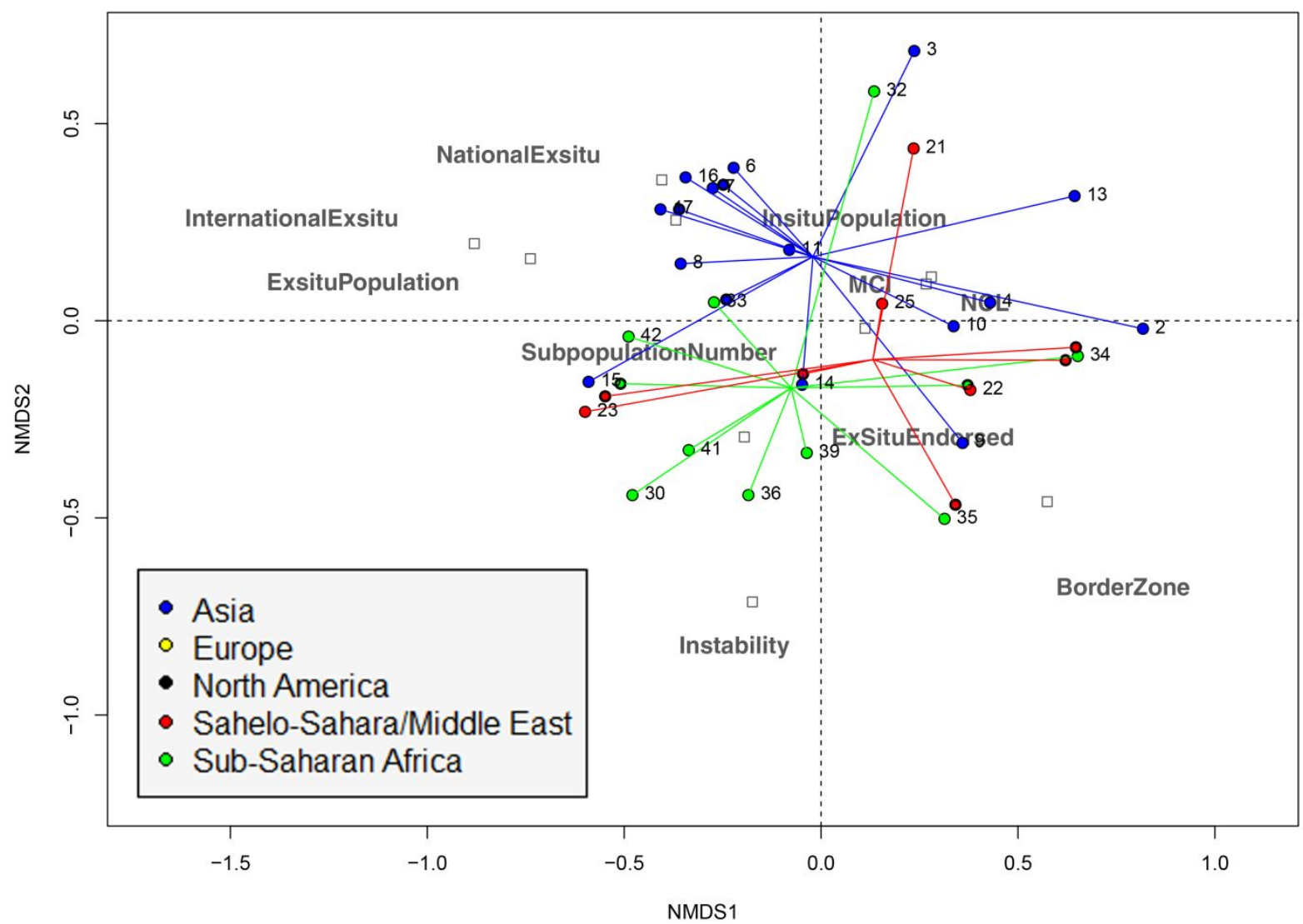

513 